\title{
Shock Wave Compression of Iron-Silicate Garnet ${ }^{1}$
}

\author{
Earl K. Graham ${ }^{2}$ and Thomas J. Ahrens \\ Seismological Laboratory, California Institute of Technology \\ Pasadena, California 91109
}

\begin{abstract}
Shock wave Hugoniot data have been obtained for almandine-garnet of composition (Fe.7n, $\left.\mathrm{Mg}_{0.14}, \mathrm{Ca}_{004}, \mathrm{Mn}_{0} \mathrm{as}\right) \mathrm{Al}_{2} \mathrm{Si}_{3} \mathrm{O}_{12}$ to pressures of $>650 \mathrm{~kb}$. The Hugoniot data indicate the onset of a high-pressure phase at $195 \pm 20 \mathrm{~kb}$. Equation-of-state systematics and crystal chemical data (stemming largely from analog compounds) suggest that the high-pressure phase occurs in an 'ilmenitelike' structure with an initial density of $4.44 \pm 0.04 \mathrm{~g} / \mathrm{cm}^{3}$. This value represents an increase of about $6 \%$ over the initial garnet density of $4.180 \pm 0.005 \mathrm{~g} / \mathrm{cm}^{3}$. The adiabatic bulk modulus $K_{0}^{8}$ and its first pressure derivative $\left(\partial K^{g} / \partial P\right)_{T}$ were calculated for the highpressure phase and found to be $3.19 \pm 0.39 \mathrm{Mb}$ and $2.6 \pm 0.7$, respectively. The major source of probable error in these values results from the indicated uncertainty in the initial density of the high-pressure phase. These results strongly suggest that upper mantle minerals are likely to occur in the ilmenite structure over a substantial part of the lower mantle.
\end{abstract}

It is generally accepted that the upper mantle of the earth is composed predominantly of some combination of the minerals olivine, pyroxene, and garnet. In particular, it has been shown by Graham [1970] that a pyrolite composition derived from a mixture of $75 \%$ alpine peridotite and 25\% Hawaiian basalt [Ringwood, 1966] satisfies the density and elasticity requirements of the upper mantle within present experimental uncertainties, as well as petrological and geochemical considerations. Data on the elastic properties and the high-pressure behavior of these minerals are essential to our understanding of the constitution and the structure of the earth's mantle.

The proportion of garnet in petrological models suggested for the upper mantle varies from about 14 wt $\%$ in the pyrolite model to over $50 \mathrm{wt} \%$ for eclogitic compositions. In addition, work by Ringwood and Major [1966] suggests that, in the presence of dissolved $\mathrm{Al}_{2} \mathrm{O}_{3}$, pyroxene is capable of transforming into a garnetlike structure. Smith and Moson's [1970] observation of this new garnet (majorite), which is close to the stoichiometry of

${ }^{1}$ Contribution 2093, Division of Geological Sciences, California Institute of Technology.

${ }^{2}$ Now at Department of Geosciences, Pennsylvania State University, University Park, Pennsylvania 16802.

Copyright (C) 1973 by the American Geophysical Union. pyroxene and presumably shock induced, in the Cooraro meteorite confirms the existence of this phase. More recently, a high-pressure phase induced in Bamle enstatite by shock wave compression has been interpreted by Ahrens and Gaffney [1971] as probably representing this same garnet structure. When the foregoing is considered, it is apparent that a significant fraction of the upper mantle could be in the garnet structure. The importance of understanding the high-pressure characteristics of garnet is thus considerably amplified.

Of primary importance, in addition to an understanding of the pressure and temperature dependence of the elastic properties of garnet per se, is the possibility of transformation to a high-pressure phase. It is instructive to consider a Goldschmidt diagram indicating the structural fields of some $\mathrm{ABO}_{3}$ compounds in relation to the ionic radii of the constituent $A$ and $B$ cations. Figure 1 shows the central and transitional positions of the garnet field in relation to the pyroxene, ilmenite, and perovskite structural fields. In addition to suggesting the garnet-pyroxene transformation discussed previously, the diagram also suggests the possibility of a garnet transformation into an ilmenite or perovskite structure under very high pressure and temperature conditions. It has been suggested by Boyd [1964] that, at sufficiently high pressure, pyrope $\left(\mathrm{Mg}_{3} \mathrm{Al}_{2} \mathrm{Si}_{8} \mathrm{O}_{12}\right)$ would invert to a solid solution between $\mathrm{MgSiO}_{3}$ 


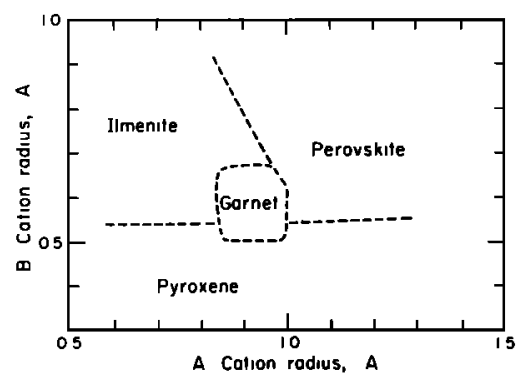

Fig. 1. Schematic diagram of the fields of pyroxene, ilmenite, perovskite, and garnet structures based on a plot of $A$ and $B$ ionic radii for $\mathrm{A}^{2+} \mathrm{B}^{4+} \mathrm{O}_{3}$ compounds possessing the indicated structures [after Ringwood, 1970].

(ilmenite) and $\mathrm{Al}_{2} \mathrm{O}_{3}$ (corundum). Partial confirmation of this supposition has been provided by Ringwood and Major's [1967a] studies of the system $\mathrm{Mg}_{3} \mathrm{Al}_{2} \mathrm{Si}_{3} \mathrm{O}_{12}-\mathrm{Mg}_{3} \mathrm{Al}_{2} \mathrm{Ge}_{3} \mathrm{O}_{12}$ at high pressure and temperature. Their data indicate a homogeneous series of ilmenite solid solutions near the germanate end of the system above $70 \mathrm{~kb}$ at about $900^{\circ} \mathrm{C}$. Although the data were inconclusive on the silicate end, Ringwood and Major projected a transformation pressure of about $200-300 \mathrm{~kb}$ for the phase transition of pyrope-garnet to an ilmenite structure. The density increase of this transformation was determined to be about $7.5 \%$. In addition to suggesting the garnet-ilmenite possibility, Figure 1 also suggests considering the perovskite structure as a high-pressure garnet phase. This supposition has also been verified experimentally by Ringwood and Major [1967b], who transformed $\mathrm{CaGeO}_{3}$ (wollastonite structure) under very high pressure into a distorted garnet structure and finally into a perovskite structure. Moreover, Marezio et al. [1966] were able to transform yttrium-iron and yttrium-aluminum garnets into a perovskite structure by using a conventional piston cylinder apparatus. The density increase of the garnet-perovskite transformation indicated by these studies is about $18 \%$. Therefore, although a high-pressure phase has not been experimentally verified as yet for an earth-forming silicate-garnet, the possibility of such a transformation is suggested strongly by the foregoing studies on analog structures and crystal chemical systematics.

The use of shock wave techniques has already revealed a number of important phase trans- formations in rocks and minerals [Wackerle, 1962; A Arens and Gregson, 1964; Ahrens and Gaffney, 1971; McQueen et al., 1967] and has provided valuable information on the equations of state of the high-pressure phases [Anderson and Kanamori, 1968; Ahrens et al., 1969]. The characterization of the properties of such highpressure phases by shock techniques has provided important information concerning compositional aspects of the earth's mantle and core [Anderson and Jordan, 1970; Ringwood, 1970].

In this study shock wave compression data to over $650 \mathrm{~kb}$ are presented for single-crystal almandine-garnet. The data indicate the initiation of a phase transformation near $200 \mathrm{~kb}$; total transition to the high-pressure polymorph occurs at approximately $300 \mathrm{~kb}$. The zero pressure density of the high-pressure phase is determined by crystal chemical arguments and supported by preliminary shock recovery experiments. When the calculated zero pressure density is used, the metastable Hugoniot of the high-pressure phase centered at room conditions is determined by assuming a form for the Grüneisen parameter consistent with the linear bulk modulus approximation. Lastly, the elastic properties of the high-pressure phase are calculated from the metastable Hugoniot data by using the linear shock velocity-particle velocity relationship.

\section{Specimen Description}

The specimen material selected for this study consisted of a single-crystal sample of almandinegarnet from Salida, Colorado. Almandine-garnet crystals from this locality were first described by Penfield and Sperry [1886]. The crystal used in the present work was a large well-formed rhombic dodecahedron of almandine lightly coated with a chloritic alteration product. Examination of the interior revealed negligible fracturing and alteration minerals. Consistency among the measured lattice parameters, the composition, and the density verify the foregoing observation; therefore the individual specimen blanks have been regarded as pore free. A schematic representation of the initial sample and the relation of the external morphology to the chosen shock propagation direction, the [100] axis, are indicated in Figure 2.

The large single crystal was initially cut into 


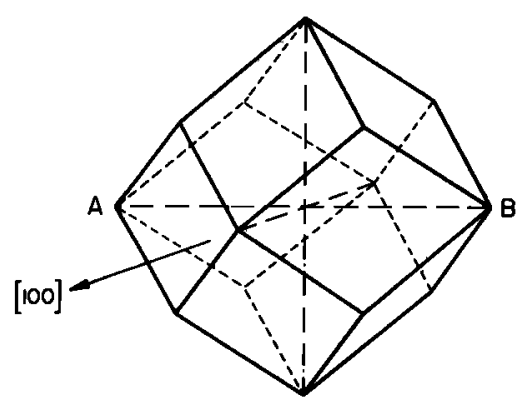

Fig. 2. Schematic representation of the rhombic dodecahedron single-crystal sample of almandine-garnet used in this study.

a series of 5-mm-thick slabs oriented perpendicular to the [100] direction. External morphology was used as a reference for orientation, and the uncertainty in this parameter is estimated to be $<3 \%$. The central slab was selected to determine the composition of the sample. A series of nine microprobe analyses were made across the slab at approximately equal intervals. Each point was probed for $\mathrm{Mg}, \mathrm{Fe}, \mathrm{Ca}, \mathrm{Mn}, \mathrm{Al}$, and Si (Figure 3). Minor 'zoning' in the proportions of the eightfold coordinated cations is evident. This feature is rather common in almandine-garnet and appears to reflect a general pattern of substitutions in the garnet molecule as a result of progressive metamorphism, $\mathrm{FeO}+\mathrm{MgO}$ substituting for $\mathrm{CaO}+\mathrm{MnO}$ with increasing metamorphic grade [Deer et al., 1962]. However, because the densities of the individual target specimen blanks were quite consistent, the compositional deviations were regarded as negligible in the final data analyses. An average bulk composition of $\left(\mathrm{Fe}_{0.78}, \mathrm{Mg}_{0.14}, \mathrm{Ca}_{0.04}\right.$, $\left.\mathrm{Mn}_{0.00}\right)_{2} \mathrm{Al}_{2} \mathrm{Si}_{8} \mathrm{O}_{12}$ was adopted for the garnet sample. This composition is consistent with the measured lattice parameter and the density within the experimental uncertainty.

In addition, several thin sections were cut from the middle section. These revealed a minimal occurrence of internal fractures and negligible alteration. The dominant mineral phase was optically isotropic almandine-garnet; however, a minor fraction of opaque grains was randomly disseminated throughout the garnet matrix. This mineral appeared as hexagonal platelets and amounted to somewhat less than $0.5 \%$ of the total volume. A microprobe analysis of the individual inclusions revealed a high proportion of $\mathrm{Ti}$ and $\mathrm{Fe}$, thus suggesting ilmenite $\left(\mathrm{FeTiO}_{3}\right)$ as the most probable composition. Although this material is of no consequence as far as the shock compression data are concerned, it hampered the $\mathrm{X}$ ray examination of the shock recovery experiment. The index of refraction of the garnet was measured at 1.802 \pm 0.003 at $24^{\circ} \mathrm{C}$. This value is consistent with the indicated composition.

The lattice parameter of the Salida garnet sample was determined by using the standard Debye-Scherrer powder diffraction method. Approximately 16 lines in the back reflection region were used in a $\cos ^{2} \theta$ extrapolation to obtain a value of $a=11.519 \pm 0.001 \mathrm{~A}$. The density of the sample, calculated from this lattice parameter and the microprobe composition, is $4.19 \pm 0.02 \mathrm{~g} / \mathrm{cm}^{3}$. The estimated uncertainty in this case is primarily the result of possible error in the indicated composition rather than in the measured lattice parameter. This value is consistent with the range of measured bulk densities of the individual target specimens.

Because of the occurrence of minor inclusions of ilmenite $\left(\mathrm{FeTiO}_{3}\right)$ in the Salida sample, recovery experiments were made on an additional

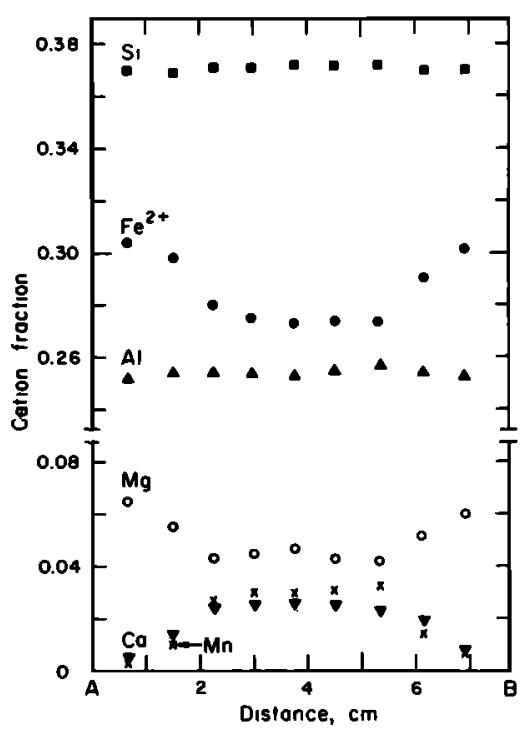

Fig. 3. Microprobe analyses of the points along the central almandine section. The line $A B$ in Figure 2 indicates the approximate locus of sample points. Electron microprobe analyses were done by A. Chodos. 
iron-rich garnet specimen (Brazil) that appeared in thin section to be completely free of included mineral impurities. After electron microprobe analysis, the particular sample selected proved to contain a significant praportion of the spessartine molecule in addition to almandine. The composition was determined to be $\left(\mathrm{Fe}_{052}, \mathrm{Mn}_{0.47}, \mathrm{Ca}_{001}\right)_{3} \mathrm{Al}_{2} \mathrm{Si}_{3} \mathrm{O}_{12}$, which is consistent with the measured density of $4.247 \pm$ $0.001 \mathrm{~g} / \mathrm{cm}^{3}$ and the lattice parameter $a=$ $11.572 \pm 0.001 \mathrm{~A}$. However, because of the similarity in the ionic radii of $\mathrm{Fe}^{2+}$ and $\mathrm{Mn}^{2+}$, there is good reason to expect that the two garnet samples will transform into equivalent structures in the high-pressure regime.

Twenty-five specimen target blanks were cored from the oriented almandine slabs. The targets were cut as cylindrical disks $18 \mathrm{~mm}$ in diameter; the faces were finished flat and parallel to a thickness of approximately $5 \mathrm{~mm}$. Individual target blanks were cored from areas of the oriented slabs that were most free from internal fracture and inhomogeneity as indicated by $\mathrm{X}$ ray radiography shadowgraphs. Bulk densities of the individual samples were measured by using the method of water immersion and are considered accurate to $\pm 0.05 \%$. The range of densities varied from 4.175 to $4.186 \mathrm{~g} / \mathrm{cm}^{3}$, except for a single blank cored from the center of the original single crystal; the variation is attributable to the slight compositional zoning previously discussed. Successful Hugoniot high-pressure data were obtained for 18 of the original garnet target blanks. The initial density and the thickness of these individual samples are indicated in Table 1. Thicknesses were measured with a comparator and are accurate to within $\pm 0.05 \%$.

\section{Shock Wave Measurementrs}

The experimental technique of generating and measuring shock waves in solids by using the Caltech high-performance gun has been described by Lower and Ahrens [1969] and Ahrens et al. [1970]. Only a brief description will be given here as being pertinent to the present problem.

The finished target blanks were mounted on 1.5-mm-thick driver plates that had been ground flat and parallel. Three types of driver plates were used: polycrystalline tungsten, density $19.2 \mathrm{~g} / \mathrm{cm}^{3}$; tungsten alloy (fansteel), density $16.9 \mathrm{~g} / \mathrm{cm}^{3}$; and aluminum 2024 , density $2.79 \mathrm{~g} / \mathrm{cm}^{3}$. Flat and inclined mirrors were placed on the sample and the driver plates to record shock arrivals at the sample-driver plate interface and at the sample free surface. The velocity of the planar shock wave through the sample was measured by recording the time between destructions of the mirror-reflecting coatings by using a xenon flash tube light source and an image converter (streak) camera [Ahrens et al., 1970]. Calibration for the film records was provided by a pulsed argon laser that was intensity modulated by a Pockels cell to provide 50 -nsec time marks. The primary source of error in the shock velocity determinations was a result of the uncertainty in the precise location of the various shock wave arrivals on the photographic records. As is indicated in Tables 1 and 2, the measured wave velocities are generally considered accurate to within $\pm 0.5 \%$.

Shock pressures from about 100 to over 650 $\mathrm{kb}$ were induced in the garnet sample blanks by impacting a flyer plate onto the target assembly. The 3.5-mm-thick flyer plates were composed of the same material as the driver plates and were embedded in the ends of specially designed Lexan projectiles. The projectiles were fired at the targets at velocities between 0.8 and $2.5 \mathrm{~km} / \mathrm{sec}$ by using the Caltech highperformance gun. Projectile velocities were measured along the last $50 \mathrm{~cm}$ of the 8 -meter barrel by using a series of three $\mathrm{He}-\mathrm{Ne}$ laser photodiode arrangements. Velocities of the flyer plates at impact, which were required for the impedance-matching method used in the Hugoniot state determinations, were generally better than $\pm 1 \%$. Appropriate shock tilt corrections resulting from nonplanar impacts of the flyer driver plates were applied when necessary.

Final Hugoniot states have been determined for the 18 shock wave experiments by using the usual Rankine-Hugoniot equations and method of impedance matching [Rice et al., 1958]. Because a double-wave structure was observed on thẽ low-pressure data, the velocity of the second wave was corrected, when necessary, for the interaction of the refraction arising from the reflection of the first shock front at the free surface, according to the method suggested by Ahrens et al. [1968]. 


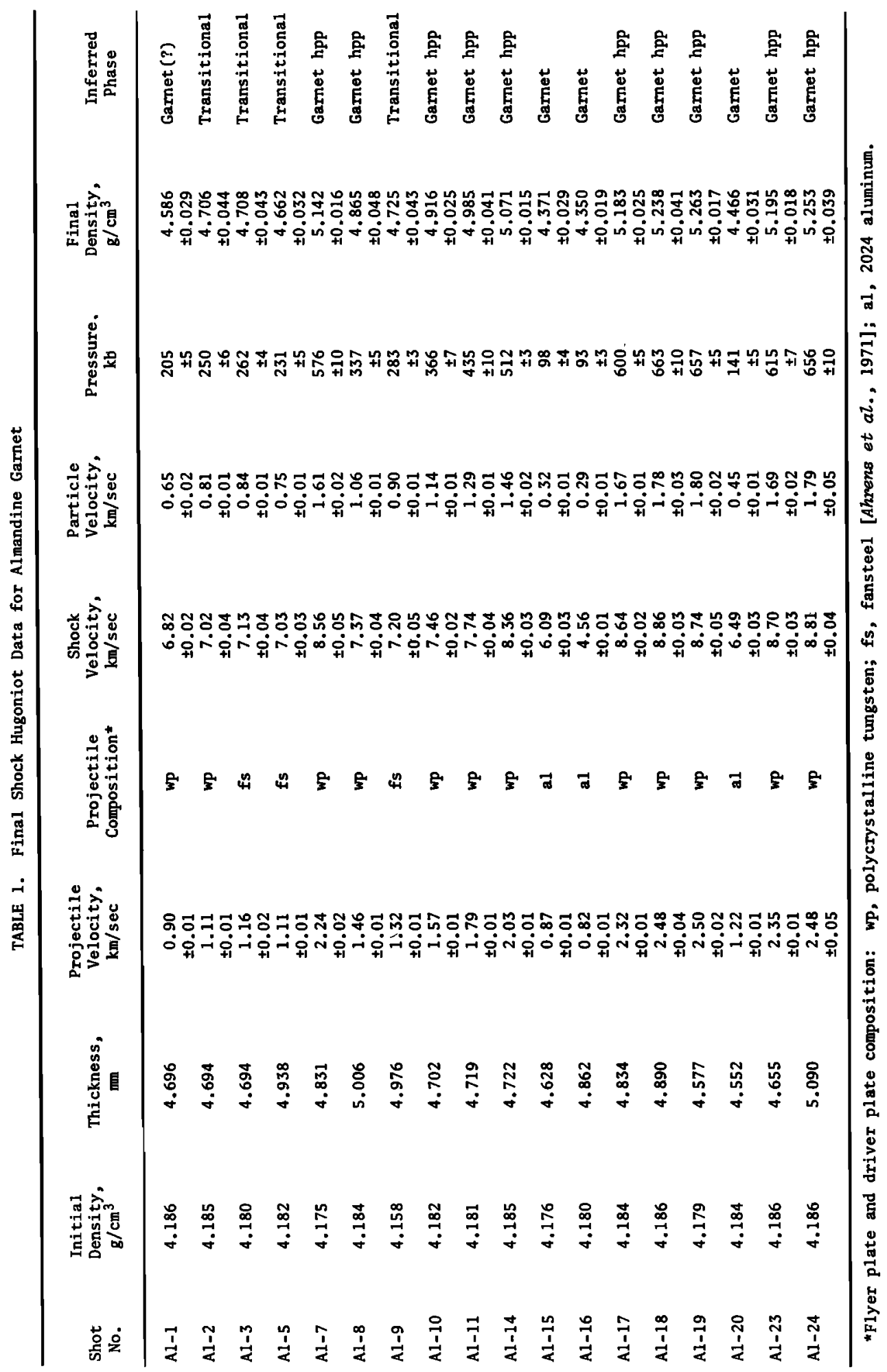




\begin{tabular}{|c|c|c|c|c|c|}
\hline $\begin{array}{l}\text { Shot } \\
\text { No. }\end{array}$ & $\begin{array}{l}\text { Initial } \\
\text { Density, } \\
\text { g/ } \mathrm{cm}^{3}\end{array}$ & $\begin{array}{l}\text { Precursor } \\
\text { Velocity, } \\
\mathrm{km} / \mathrm{sec}\end{array}$ & $\begin{array}{l}\text { Particle } \\
\text { Velocity, * } \\
\mathrm{km} / \mathrm{sec}\end{array}$ & $\underset{\mathrm{kb}}{\text { Amplitude, }}$ & $\begin{array}{c}\text { Precursor } \\
\text { Density, } \\
\mathrm{g} / \mathrm{cm}^{3}\end{array}$ \\
\hline$A l-1$ & 4.186 & $\begin{array}{r}8.27 \\
\pm 0.02\end{array}$ & $\begin{array}{r}0.33 \\
\pm 0.02\end{array}$ & $\begin{array}{r}114 \\
\pm 7\end{array}$ & $\begin{array}{r}4.360 \\
\pm 0.011\end{array}$ \\
\hline$A 1-2$ & 4.185 & $\begin{array}{r}8.38 \\
\pm 0.04\end{array}$ & $\begin{array}{r}0.22 \\
\pm 0.02\end{array}$ & $\begin{array}{l}77 \\
\pm 7\end{array}$ & $\begin{array}{r}4.298 \\
\pm 0.011\end{array}$ \\
\hline $\mathrm{Al}-3$ & 4.180 & $\begin{array}{r}8.44 \\
\pm 0.03\end{array}$ & $\begin{array}{r}0.28 \\
\pm 0.01\end{array}$ & $\begin{array}{l}99 \\
\pm 4\end{array}$ & $\begin{array}{r}4.323 \\
\pm 0.005\end{array}$ \\
\hline$A 1-5$ & 4.182 & $\begin{array}{r}8.20 \\
\pm 0.03\end{array}$ & $\begin{array}{r}0.20 \\
\pm 0.01\end{array}$ & $\begin{array}{l}69 \\
\pm 3\end{array}$ & $\begin{array}{r}4.287 \\
\pm 0.005\end{array}$ \\
\hline$A 1-8$ & 4.184 & $\begin{array}{r}8.23 \\
\pm 0.02\end{array}$ & $\begin{array}{r}0.31 \\
\pm 0.01\end{array}$ & $\begin{array}{l}107 \\
\pm 10\end{array}$ & $\begin{array}{r}4.348 \\
\pm 0.016\end{array}$ \\
\hline$A 1-9$ & 4.158 & $\begin{array}{r}8.30 \\
\pm 0.04\end{array}$ & $\begin{array}{r}0.29 \\
\pm 0.02\end{array}$ & $\begin{array}{r}100 \\
\pm 3\end{array}$ & $\begin{array}{r}4.308 \\
\pm 0.006\end{array}$ \\
\hline$A 1-10$ & 4.182 & $\begin{array}{r}8.75 \\
\pm 0.03\end{array}$ & $\begin{array}{r}0.19 \\
\pm 0.02\end{array}$ & $\begin{array}{l}70 \\
\pm 7\end{array}$ & $\begin{array}{r}4.274 \\
\pm 0.010\end{array}$ \\
\hline$A 1-11$ & 4.181 & $\begin{array}{r}8.82 \\
\pm 0.03\end{array}$ & $\begin{array}{r}0.38 \\
\pm 0.03\end{array}$ & $\begin{array}{l}140 \\
\pm 11\end{array}$ & $\begin{array}{r}4.369 \\
\pm 0.015\end{array}$ \\
\hline $\mathrm{Al}-15$ & 4.176 & $\begin{array}{r}9.07 \\
\pm 0.04\end{array}$ & $\begin{array}{r}0.15 \\
\pm 0.01\end{array}$ & $\begin{array}{l}57 \\
\pm 4\end{array}$ & $\begin{array}{r}4.246 \\
\pm 0.005\end{array}$ \\
\hline $\mathrm{Al}-16$ & 4.180 & $\begin{array}{r}8.58 \\
\pm 0.01\end{array}$ & $\begin{array}{r}0.24 \\
\pm 0.01\end{array}$ & $\begin{array}{l}86 \\
\pm 4\end{array}$ & $\begin{array}{r}4.300 \\
\pm 0.005\end{array}$ \\
\hline $\mathrm{Al}-20$ & 4.184 & $\begin{array}{r}8.48 \\
\pm 0.03\end{array}$ & $\begin{array}{r}0.18 \\
\pm 0.01\end{array}$ & $\begin{array}{l}64 \\
\pm 3\end{array}$ & $\begin{array}{r}4.275 \\
\pm 0.005\end{array}$ \\
\hline
\end{tabular}

*Assumed to be one-half the measured free surface velocities.

\section{Experimental Results}

The data for the final Hugoniot high-pressure states are indicated in Table 1 and Figure 4. The total range of data represents about a $25 \%$ compression of the initial almandinegarnet over a range $0-650 \mathrm{~kb}$. It is apparent from Figure 4 that three separate regimes of compression characterize the data. These regimes have been interpreted to represent an initial range of compression involving the almandine-garnet phase, a transition range characterized by partial transformation into a highpressure phase (hpp), and, finally, the intrinsic compression of the shock-induced high-pressure phase (garnet hpp).

Compression of the garnet initial phase occurs along the Hugoniot to approximately 200 $\mathrm{kb}$. Within this regime the shock wave compression states are consistent with the ultra- sonic data of Soga [1967] obtained on an almandine-garnet of similar composition. The indicated (adiabatic) compression of Soga's sample was calculated by using the Murnaghan and third-order Birch-Murnaghan equations of state. The pertinent parameters for Soga's specimen, $\rho_{0}=4.160 \mathrm{~g} / \mathrm{cm}^{s}, K^{s}=1770 \mathrm{~kb}$, and $\left(\partial K^{B} / \partial P\right)_{T}=5.43$, are considered appropriate for comparison with the present data. In addition to the acoustic work, isothermal static compression data were obtained for the garnet measured by Soga by Takahashi and Liu [1970] by using a diamond anvil $\mathrm{X}$ ray apparatus with a $\mathrm{NaCl}$ pressure standard. These data are also consistent with the present results; deviations above $200 \mathrm{~kb}$ are considered related to reaction kinetics. Above $200 \mathrm{~kb}$ the shock Hugoniot data indicate an abnormally high compression in relation to extrapolations 
of the garnet equation of state. This high compression represents the onset of a mixed garnet-garnet hpp transition zone, which persists to approximately $300 \mathrm{~kb}$.

Above $300 \mathrm{~kb}$ and up to the highest pressures attained in this study (slightly over 650 kb) the Hugoniot data are characterized by a fairly constant offset below the garnet equationof-state trajectories. This region probably represents the Hugoniot of the homogeneous highpressure phase. Examination of the off set suggests a density increase of approximately 5\% between the garnet and garnet hpp phases. Considerable effort is made in later sections to infer the probable structure and the elastic properties of the high-pressure phase.

On all shots with a final pressure less than $470 \pm 40 \mathrm{~kb}$ a double-wave structure was ob- served. The initial shock wave was characterized by velocities between 8.20 and $9.07 \mathrm{~km} / \mathrm{sec}$ and amplitudes between 57 and $140 \mathrm{~kb}$. However, the average velocity, $8.5 \pm 0.2 \mathrm{~km} / \mathrm{sec}$, is consistent with the elastic compressional wave velocity, $8.52 \pm 0.01 \mathrm{~km} / \mathrm{sec}$, which was measured for the garnet sample in the [100] direciion by using acoustic interferometry. Compressional wave velocities were measured on four of the oriented Salida garnet target blanks (Al-4, $\mathrm{Al}-7, \mathrm{Al}-9$, and $\mathrm{Al}-12$ ) prior to the shock experiment. A modified phase comparison technique [Spetzler, 1970] over a frequency range 10-30 $\mathrm{MHz}$ was used in the measurements. The average value, indicated previously, yields a value of $3040 \pm 15 \mathrm{~kb}$ for $C_{11}{ }^{s}$, the adiabatic second-order elastic coefficient for almandinegarnet. This value is consistent with the $C_{11}{ }^{\mathrm{s}}$

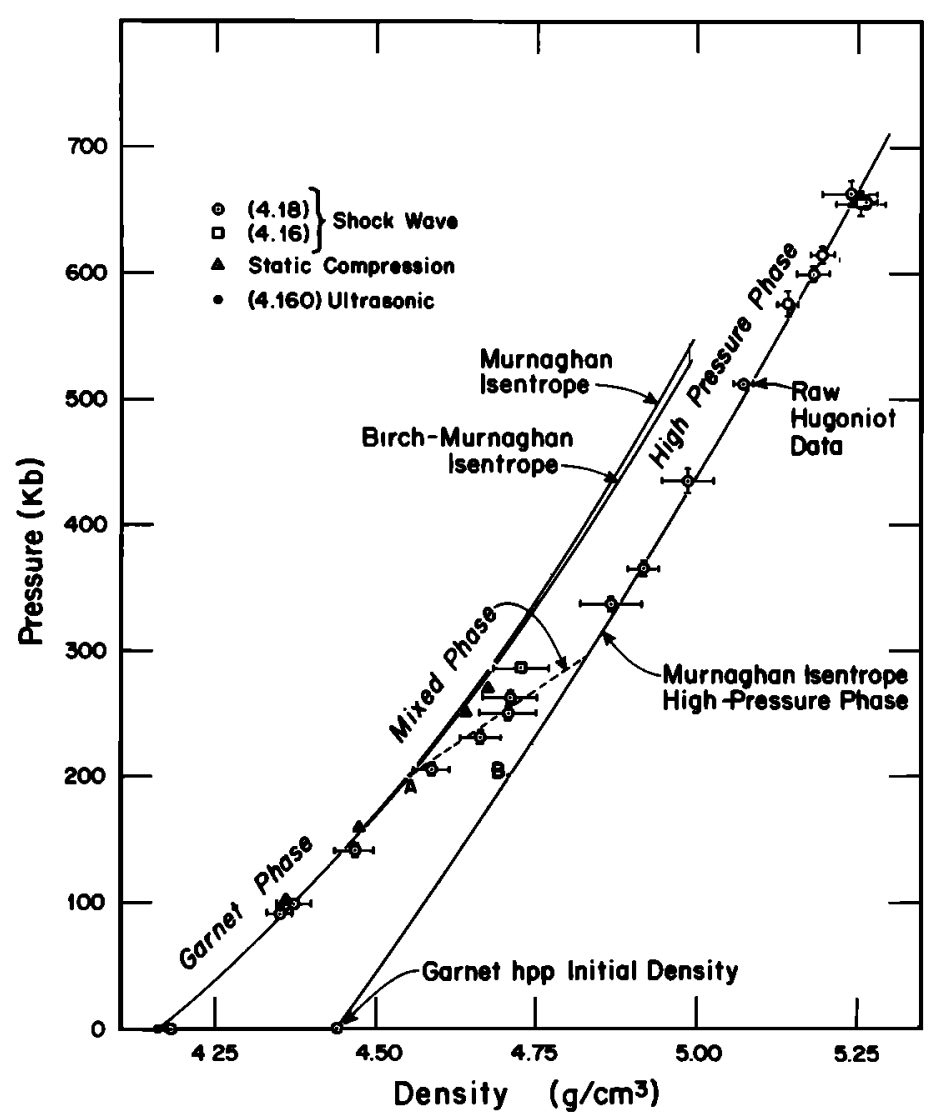

Fig. 4. The final Hugoniot compression states reached in the shock wave experiments. Ultrasonic data [Soga, 1967] and isothermal compression data [Takahashi and Liu, 1970] for an almandine-garnet specimen of composition similar to that of the present study are indicated for comparison. 
value measured by Soga [1967]. Therefore the initial low-pressure wave appears to represent an elastic precursor, a one-dimensional compression wave in which internal rearrangement of the garnet sample has not yet taken place.

The final Hugoniot states have also been determined in the shock velocity-particle velocity plane (Figure 5). However, when a double shock front occurs, as it does in the present situation, the measured shock velocity values (Table 1) reflect the interaction of the second wave with the reflection of the elastic precursor off the free surface. Therefore the 'effective' shock velocities [Wackerle, 1962] have been calculated according to

$$
U_{\mathrm{a}}^{*}=\left[\rho P_{H} / \rho_{0}\left(\rho-\rho_{0}\right)\right]^{1 / 2}
$$

and

$$
u_{p}^{*}=\left[P_{H}\left(\rho-\rho_{0}\right) / \rho \rho_{0}\right]^{1 / 2}
$$

where $P_{H}$ and $\rho$ represent points along the measured Hugoniot. These represent the true shock and particle velocities at pressures high enough that the 'second' wave is the only wave in the shock process. The ranges of the various phases, corresponding to the density-pressure representation in Figure 4, are also indicated in Figure 5.

\section{Initial Density of High-Pressure Phase}

Reducing the shock Hugoniot data of the high-pressure phase involves the recovery of three important material properties: the zero pressure density $\rho_{0}$, the isentropic bulk modulus $K_{0} \mathbf{s}$, and the isothermal pressure derivative of the isentropic bulk modulus $\left(\partial K_{0}{ }^{8} / \partial P\right)_{T}$. However, regardless of the methodology chosen for reducing the measured raw Hugoniot data, it has been pointed out by McQueen et al. [1967, p. 5020] that, although there is a combination of the above unknown parameters '. . . that gives the best fit, the experimental data are usually not good enough to warrant this selection. However, the data do appear good enough to determine two of the parameters if the third is specified.' Consequently, various investigators have sought to constrain one or more of the unknown parameters to calculate the others. The usual method is to determine the zero pressure density $\rho_{0}$ of the unknown high-pressure phase by using various empirical relations involving bulk modulus-density systematics of similar materials [e.g., Anderson and Kanamori,

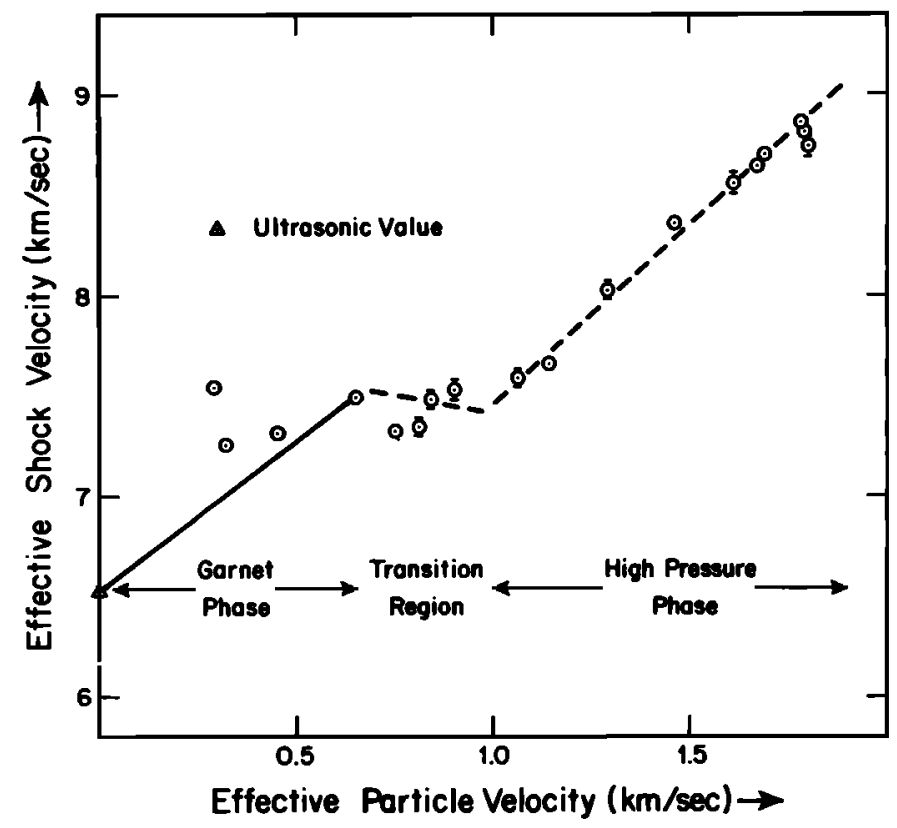

Fig. 5. Effective shock velocity-particle velocity representation. The various phase regimes are indicated, as is the acoustic value of Soga [1967]. 
1968; Wang, 1967; Ahrens et al., 1969]. In this study two approaches were followed: (1) the most probable garnet hpp structure was inferred from analog studies, and the density was defined by using crystal chemical systematics; and (2) recovery measurements were attempted, and the products were examined by using $\mathrm{X}$ ray techniques.

There are essentially two modes by which garnet may achieve a higher density state: (1) transformation of the basic $\mathrm{ABO}_{3}$ compound into a single mineral component involving a structural modification or an increase of coordination of the $A$ and/or $B$ cations or both; or (2) a disproportionation reaction in which two or more high-pressure mineral components are the products. In the second case, analog studies present several possibilities. Breakdown of the ( $\mathrm{Fe}, \mathrm{Mg}, \mathrm{Ca}, \mathrm{Mn})_{3} \mathrm{Al}_{2} \mathrm{Si}_{3} \mathrm{O}_{12}$ garnet into its component oxides is a primary consideration. The calculated density of the component oxides of the Salida garnet sample is $4.66 \mathrm{~g} / \mathrm{cm}^{2}$, which represents an $11.5 \%$ increase over the initial garnet density. The offset of the Hugoniot data in Figure 4 above the extrapolated garnet isentrope is approximately $5 \%$, if small corrections for thermal pressure and the energy of transition are neglected. Therefore disproportionation into component oxides does not appear likely. A disproportionation reaction into $\mathrm{Al}_{2} \mathrm{O}_{3}+$ $3(\mathrm{Fe}, \mathrm{Mg}, \mathrm{Ca}, \mathrm{Mn}) \mathrm{SiO}_{\mathrm{s}}$, where the latter reactant may occur in the pyroxene, ilmenite, or perovskite structures, is also a possibility. However, none of these combinations is compatible with the observed density increase. Moreover, with regard to such disproportionation reactions Ahrens et al. [1969] have pointed out that the type of transformation that actually occurs under shock conditions will be determined by both thermodynamic and kinetic factors. In the submicrosecond duration of the passage of a shock wave, kinetic factors will favor transformation into a single homogeneous phase if a suitable structure exists. For these reasons a disproportionation reaction has been abandoned in favor of transition into a single high-pressure mineral phase.

Precedents for the transformations of $\mathrm{ABO}_{z}$ compounds, based on analog studies of germanates and related materials [e.g., Ringwood, 1970], have been discussed in the introduction. The most probable are the ilmenite and perov- skite structures. In addition, less likely possibilities are $A$ and $B$ rare earth structures. Again, when the approximate density increase of $5 \%$ indicated by the Hugoniot data is considered, the excessive density increases associated with a garnet- $B$ rare earth $(7-9 \%)$ or a garnetperovskite (16-18\%) transformation as estimated from analog studies [e.g., Ringwood, 1970; Reid and Ringwood, 1969] appear to preclude these transitions as explanations of the present data. Therefore the most probable transformation consistent with the garnet $\mathrm{Hu}$ goniot data involves a high-pressure phase in the ilmenite or corundum structures. For the almandine-garnet under consideration, because of the differences in the ionic radii of the primary $\mathrm{Fe}^{2+}, \mathrm{Al}^{3+}$, and $\mathrm{Si}^{4+}$ cations, an ordered relationship would be expected among the cations within an approximate hexagonal closepacked oxygen anion framework. However, because of the short duration of the shock transformation, long-range disorder would be more likely. Therefore the degree to which the structure actually produced under shock conditions is more 'ilmenitelike' or 'corundumlike' is not clear. Because the ilmenite structure is most probable under equilibrium conditions and is therefore to be associated with possible application to the mantle, we prefer an ilmenitelike structure as the most reasonable alternative.

As was previously discussed, the reduction methodology used in analyzing the garnet hpp Hugoniot data requires specification of the initial density. An estimate of the density of compounds of $\mathrm{ABO}_{3}$ stoichiometry is provided by molar volume relationships. Reid and Ringwood [1969] have prepared graphs of average metal-oxygen (octahedral) bond length versus molar volume for a number of $\mathrm{ABO}_{3}$ and $\mathrm{M}_{2} \mathrm{O}_{3}$ compounds in their appropriate structural forms. The relevant data for compounds in ilmenite and corundum structures have been plotted in Figure 6. These data have been fit by least squares to a quadratic equation, the locus of which also is indicated in Figure 6. The average octahedral cation-anion bond length for $\left(\mathrm{Fe}_{\text {0.78 }}, \mathrm{Mg}_{0.14}, \mathrm{Ca}_{0.04}, \mathrm{Mn}_{0.03}\right)_{3} \mathrm{Al}_{2} \mathrm{Si}_{3} \mathrm{O}_{12}$ garnet hpp was estimated from the component simple oxides. The result, $\mathrm{M}-\mathrm{O}_{\mathrm{avg}}=1.946 \mathrm{~A}$, in conjunction with the quadratic fit to the corundum-ilmenite data, yields a value of $44.6 \pm 0.8$ $A^{3}$ for the volume per formula unit of garnet 


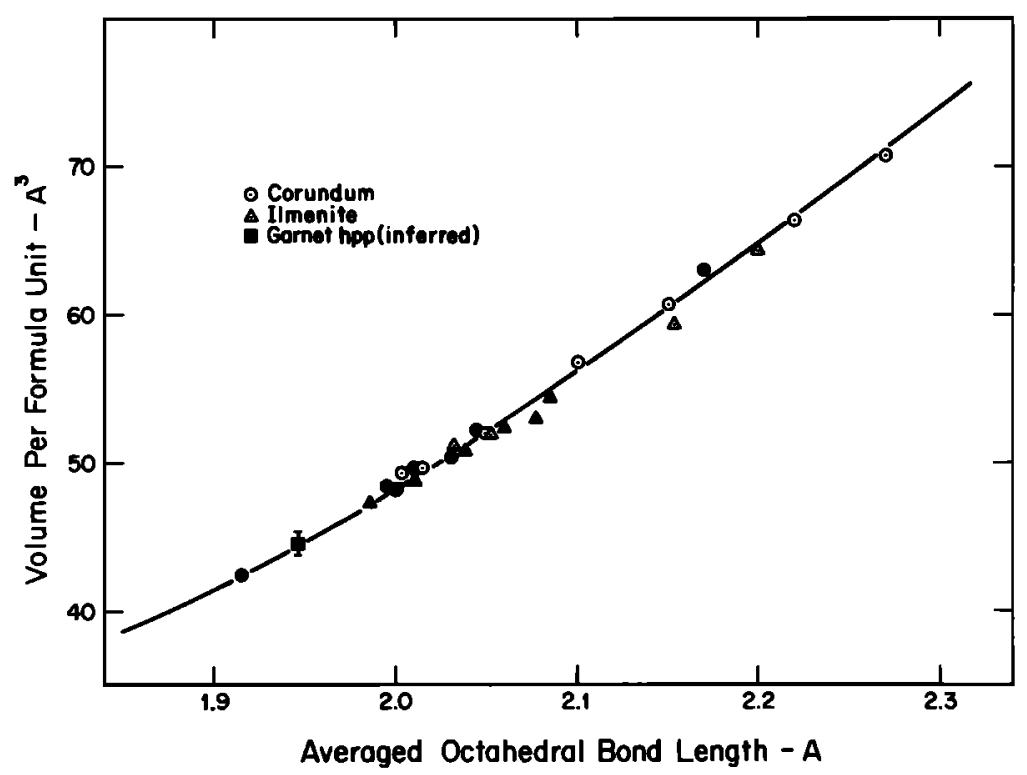

Fig. 6. Averaged octahedral bond lengths versus volume per formula unit for $\mathrm{M}_{2} \mathrm{O}_{3}$ and $\mathrm{ABO}_{3}$ compounds having corundum and ilmenite structures [after Reid and Ringwood, 1969]. Solid symbols refer to bond lengths determined from atomic coordinates, and open symbols to bond lengths estimated from simple oxides. The inferred volume per formula unit for ilmenitelike garnet hpp also is indicated.

hpp. The gram formula weight of the sample is 120.62 grams. Therefore the calculated density of the garnet hpp phase is $4.48 \pm 0.08 \mathrm{~g} / \mathrm{cm}^{3}$. In addition, a similar relation involving the molar volume and the ionic radii of the individual $A$ and $B$ cations in ilmenite compounds was used by Ahrens and Graham [1972] to arrive at an estimated density of approximately $4.41 \mathrm{~g} / \mathrm{cm}^{3}$.

To clarify and refine the density and the structure of the high-pressure phase, an attempt was made to recover shocked specimens of garnet hpp. Although some question has been raised about the relation of shock-induced phase changes to the recovered material [Wang, 1967], the recovery of shock-induced stishovite from quartz by J. D. Kleeman (personal communication, 1971) suggests the possible application of this technique to other materials. The method is explained in some detail by $H$ örz and Ahrens [1969] and Gibbons and Ahrens [1971]. Essentially, it involves embedding small disks of the sample $(4.75 \mathrm{~mm}$ in diameter and $0.15 \mathrm{~mm}$ thick) within large stainless-steel 304 target holders, which, in turn, are impacted by high-velocity flyer plates. The sample itself is encapsulated within a smaller stainless-steel 304 cylindrical container that releases intact from the target holder after the passage of the shock wave. The shocked specimen may then be removed from the steel container and examined by using $X$ ray and optical methods. Peak pressure within the specimen may be determined by an impedance match solution based on the flyer plate velocity and the release adiabat characteristics of both the target holder and the flyer plate materials [e.g., Gibbons and Ahrens, 1971]. For the garnet work, tungsten flyer plates were launched at the target in 20$\mathrm{mm}$ Lexan projectiles fired from a smooth-bore solid propellant gun.

The recovered samples of garnet, shocked to approximately $400-500 \mathrm{~kb}$, were examined optically and by standard Debye-Scherrer $\mathrm{X}$ ray powder diffraction methods using $\mathrm{FeK}_{\alpha}$ radiation and a $\mathrm{Mn}$ filter. Optical examination of the recovered samples indicated no suggestion of mineral phases other than the original garnet. However, the individual grains showed many characteristics of intense deformation. Particu- 
larly dominant were two sets of internal fracture planes at $90^{\circ}$ to each other. These are likely to be due to parting on $\{110\}$ owing to the sudden release of pressure after passage of the shock wave; this type of parting occurs occasionally in natural garnets. Apparently, very little, if any, of the garnet material had been retained in the high-pressure phase. This observation was verified by $\mathbf{X}$ ray examination.

Initially, a standard Debye-Scherrer photograph was obtained for unshocked Salida garnet to be used as a basis for comparison with the shocked specimens. A 73-hour exposure produced 48 lines, all of which could be indexed as almandine-garnet except for two, which proved to represent two dominant ilmenite $\left(\mathrm{FeTiO}_{3}\right)$ lines when they were compared with American Standard Testing Material data. This exposure confirmed the presence of ilmenite inclusions within the Salida sample and indicated the necessity for this consideration in the analyses of the shocked sample $X$ ray data. Several Debye-Scherrer photographs were then taken of two shocked Salida garnet specimens at various exposure times. Examination of these data, which involved exposure times of up to 100 hours, indicated the presence of several 'extra lines,' which did not appear on the Salida garnet standard and/or could not be indexed as garnet or ilmenite $\left(\mathrm{FeTiO}_{3}\right)$. It should be pointed out that all these lines were rated as $<1$ by a visual intensity estimate (maximum of 10 ) ; because the lines were so vaguely defined, no relative intensity differences could be estimated. As a result of the ilmenite $\left(\mathrm{FeTiO}_{3}\right)$ inclusions noted in the Salida garnet sample, a shock recovery experiment was also made on the garnet sample from Brazil. Several extra lines also were recovered in the analysis of the $\mathrm{X}$ ray data from this sample. However, only three lines out of eight appeared to be consistent between the two sets of photographs.

The paucity of data, the large uncertainties, and the lack of relative intensities preclude a unique structural interpretation in terms of a single high-pressure phase. In addition, it is not clear that the indicated lines even represent a single phase. Indeed, the subsequent heating effect associated with the passage of a shock wave suggests the possibility of the formation of phases unrelated to the phase observed in the Hugoniot data. Therefore the powder diffraction data for a number of iron-silicate minerals and oxides were compared with the observed extra lines. These materials include $\alpha$ and $\beta$ quartz, coesite, stishovite, fayalite, $\mathrm{Fe}_{2} \mathrm{SiO}_{4}$ (spinel), orthoferrosilite, clinoferrosilite, corundum, wustite, and hematite. In no instance could a consistent pattern be associated with any one mineral or any combination of these minerals in relation to the eight extra lines.

If the assumption is made that the observed extra lines do represent the remnants of a single high-pressure phase as defined by the basic Hugoniot data, an effort may be made to index the $X$ ray data. In view of the results of the investigation into possible $\mathrm{ABO}_{3}$ structures, a preliminary effort was made to index the lines as hexagonal with $a$ and $c$ lattice parameters appropriate for the corundum or ilmenite structures. However, the $d$ spacing data could not be satisfied with such an interpretation. The data appear to require a structure with lower symmetry and therefore have been indexed tentatively as orthorhombic by Ahrens and Graham [1972]. Although the relation between the orthorhombic interpretation and the ilmenitelike inference from crystal chemical arguments is not clear, it is not unreasonable to envisage a 'distorted' modification of the basic ilmenite structure under shock conditions. Unfortunately, the quality of data does not warrant an accurate crystal structure determination. The density determined from the orthorhombic indexing is $4.44 \pm 0.06 \mathrm{~g} / \mathrm{cm}^{2}$, which is consistent with the determinations based on crystal chemical systematics discussed previously. Moreover, because this value is a representative average of the density estimates, it is adopted as the zero pressure density of the garnet hpp and used in all the subsequent Hugoniot data reduction.

\section{Hugoniot Data Reduction}

The pressure-density relation for a material that undergoes a shock-induced phase transformation has been described by McQueen et al. [1967] and Ahrens et al. [1969]. It is convenient to first reduce the experimental Hugoniot data for the high-pressure phase to a metastable Hugoniot, which represents the shock wave data 
centered on the zero pressure density of the new phase. From the metastable Hugoniot data, it is then possible to derive, by using an appropriate equation of state, the isentrope and the isotherms of the high-pressure phase. The material properties are specified in accordance with the equation of state selected to represent the data. In the present analysis we use the fact that shock wave data are approximately linear in the shock velocity-particle velocity $\left(U_{s}-u_{p}\right)$ plane within experimental error. The parameters of the linear $U_{s}-u_{p}$ relation, when they are combined with the Murnaghan equation of state, yield directly the appropriate compression of the high-pressure phase.

The initial problem is to correct the basic experimental Hugoniot data of the high-pressure phase to corresponding points consistent with the metastable Hugoniot. This procedure amounts to making a small pressure correction for a given $\left(\rho, P_{H}\right)$ Hugoniot data point. It has been shown by McQueen et al. [1963] that it is possible to calculate a particular Hugoniot from a known Hugoniot centered at different initial conditions. The appropriate relation, which follows from the basic definition of the volume-dependent Grüneisen parameter $\gamma$ and the Rankine-Hugoniot relations, may be written as

$$
\begin{aligned}
\gamma(x)= & 2 x(1-x)\{\delta[s(1-x)-1] \\
& +2 s x\}+2 x^{2}[1-s(1-x)] \\
& +4 x(1-x)^{2} \nu \cdot\left\{2(1-x)^{3}{ }^{2}\right. \\
& +(1-x)^{2}[\delta(s(1-x)-1)+2 s x] \\
& +(1-x)(1+x)[1-s(1-x)] \\
& \left.+\left(2 C_{p} / \alpha{C_{0}}^{2}\right)[1-s(1-x)]^{3}\right\}^{-1}
\end{aligned}
$$

where $x \equiv \rho_{0} / \rho, C_{0}$, and $s$ are the parameters in the linear $U_{s}-u_{p}$ relation, $C_{p}$ is the specific heat at constant pressure, and $\alpha$ is the volume thermal expansion. The parameter $\delta$ appearing in (4) is the Anderson-Grüneisen parameter and is defined as

$$
\delta=\left.\frac{1}{\alpha K^{s}}\left(\frac{\partial K^{s}}{\partial T}\right)\right|_{p=0}
$$

where $K^{s}$ is the adiabatic bulk modulus. In addition, the parameter $v$ is given by

$$
\nu=\left.\frac{1}{\alpha}\left(\frac{\partial s}{\partial T}\right)\right|_{p=0}
$$

The preceding expression for $\gamma(x)$ may be used in (3) to calculate the metastable Hugoniot.

The use of (4) is dependent on whether the various parameters appearing in the relation can be evaluated. The quantities $C_{p}$ and $\alpha$ are

$$
P_{M}=\frac{P_{H}\left\{1-\gamma / 2\left[\left(\rho / \rho_{0}\right)-1\right]\right\}-\gamma \rho\left(E_{0}-E_{0}{ }^{h}\right)}{1-\gamma / 2\left[\left(\rho / \rho_{0}{ }^{h}\right)-1\right]}
$$

Here $\rho_{0}$ and $E_{0}$ and $\rho_{0}{ }^{n}$ and $E_{0}{ }^{n}$ refer to initial conditions for the low- and high-pressure phases, respectively, where $E$ represents specific internal energy. To apply (3) and calculate pressure on the metastable Hugoniot $P_{M}$, it is necessary to know $\gamma(\rho)$ for the high-pressure phase and the energy of transition $\Delta E_{\mathrm{tr}}=E_{0}$ - $E_{0}{ }^{h}$ (evaluated at ambient conditions).

A relation for calculating the volume dependence of the quasi-harmonic Grüneisen parameter $\gamma(\rho)$ in the classical temperature region has been derived by Pastine and Forbes [1968]. This relation is exact, provided that $U_{s}$ is given rigorously by $U_{s}=C_{0}+s u_{p}$ along each individual Hugoniot. We assume this to be the case in the present analysis. The Pastine-Forbes relation is given by generally available in the literature for most oxides and silicates; however, for high-pressure phases these properties must be calculated or estimated. In addition, the quantity $\left(\partial K^{s} / \partial T\right)_{p}$, available from ultrasonic data for many lowpressure phase materials, must be evaluated to define the parameter $\delta$. In some cases, $\delta$ may be evaluated by using the WachtmanAnderson relation [Anderson, 1966]. The quantity $v$ is difficult to evaluate; however, an approximation has been provided by Pastine [1970]:

$$
\nu \simeq s / 4\left(\gamma_{0}+2-s\right)
$$

where $\gamma_{0}$ is the Grüneisen parameter evaluated at ambient conditions. Equation 5 was originally determined for cubic solids; however, there is 
reason to expect that it would also be appropriate for noncubic solids. In a following section it is shown that all the parameters appearing in (4) can be satisfactorily estimated for garnet hpp.

In addition to (4), several other expressions for the Grüneisen parameter have been in common use by previous investigators in reducing shock Hugoniot data [Slater, 1963; Dugdale and MacDonald, 1953]. These relations for $\gamma$ have been based on particular assumptions involving the vibrational modes of lattice dynamic models. However, it has been pointed out by Knopoff and Shapiro [1969] that the results for $\gamma(x)$ calculated by these expressions are not mutually consistent and do not yield the thermodynamic value for $\gamma$ at ambient conditions. Equation 4 avoids these difficulties and reduces the number of approximations required to a minimum [O'Keeffe, 1970], because $\dot{\gamma}(x)$ has been determined directly from the thermodynamic definition $\gamma=V(\partial P / \partial E)_{v}$, where $V$ is the specific volume, rather than from a lattice dynamic model. Equation 4 has been used by O'Keeffe [1970] to evaluate accurate pressure, volume, and temperature relations for copper from Hugoniot data.

The quantities $\alpha, C_{p}$, and $\delta$, which appear in (4), are not available for garnet hpp and therefore must be estimated from ancillary data. The thermal expansion $\alpha$ is an anharmonic parameter and as such is difficult to model theoretically unless higher-order terms in the potential function are defined. It is assumed for the present problem that the thermal expansion of a complex oxide compound can be represented by the weighted volumetric average of the individual component oxides, provided valence and coordination are consistent. That is,

$$
\alpha=\sum_{i} \alpha_{\imath} V_{\imath} / \sum_{i} V_{\imath}
$$

where $V_{\imath}$ and $a_{\mathfrak{i}}$ are the molar volume and the thermal expansion of the $i$ th component oxide, respectively. From several estimates of the thermal expansion of known silicates using (6), it appears that such estimates should be accurate to within $\pm 20 \%$. The specific heat at constant pressure is estimated according to

$$
C_{p}=\sum_{i} C_{p_{i}} M_{i} / \sum_{i} M_{\imath}
$$

where $C_{\boldsymbol{p}_{i}}$ and $M_{\mathfrak{i}}$ are the specific heat and the gram formula weight of the $i$ th component oxide, respectively. Specific heats estimated from (7) should be accurate to within $\pm 2 \%$ on the basis of the results of several calculated examples. The appropriate quantities calculated for garnet hpp by using (6) and (7) are $\alpha=$ $23\left(10^{-6}\right) /{ }^{\circ} \mathrm{K}$ and $C_{p}=7.37\left(10^{\circ}\right) \mathrm{ergs} / \mathrm{g}{ }^{\circ} \mathrm{K}$. Appropriate data for $\mathrm{FeO}$ (wustite), $\mathrm{MgO}$, $\mathrm{Al}_{2} \mathrm{O}_{3}$, and $\mathrm{SiO}_{2}$ (stishovite), all of which involve sixfold coordinated cations, were used in the calculations.

Anderson et al. [1968] have compiled values of the Anderson-Grüneisen parameter $\delta$ for a number of oxides and silicates. Although there appears to be some correlation between $\delta$ and $\gamma_{0}$, the relation is not clear. Examination of the data indicates that most of the values for $\delta$ fall between 2.0 and 8.0. For garnet hpp a value of $6.0 \pm 2.0$ is used; it will later be shown that uncertainty in this parameter has little effect on the calculated high-pressure phase material properties.

In addition to $\gamma(x)$ in (3), it is necessary to know the energy of transition $\Delta E_{\mathrm{tr}}=\dot{E}_{0}-$ $E_{0}{ }^{n}$, the difference between the specific internal energies of the low- and high-pressure phases at ambient conditions. A method of approximating this quantity by using the fact that the Gibbs free energy is constant across a phase transition has been given by McQueen et al. [1963]. Assuming that the change in entropy results in a negligible specific internal energy change in relation to the $P \Delta V$ term, we can write

$$
\begin{gathered}
\Delta E_{\mathrm{tr}}=E_{0}{ }^{h}-E_{0}=\left\{\left[\left(\rho_{p}{ }^{h}-\rho_{p}\right) / \rho_{p}{ }^{h} \rho_{p}\right]\right. \\
\left.+\left[\left(\rho_{0}{ }^{h}-\rho_{0}\right) / \rho_{0}{ }^{h} \rho_{0}\right]\right\} P / 2
\end{gathered}
$$

where the subscript $p$ indicates density to be taken at the transformation pressure $P$. The transformation pressure has been estimated from the basic Hugoniot compression data and is indicated as point $\mathrm{A}$ in Figure 4; this point corresponds to density $\rho_{p}$ in (8). Point B, estimated by extrapolating the garnet hpp $\mathrm{Hu}-$ goniot data to the transformation pressure $P$, represents $\rho_{p}{ }^{n}$. Substituting these values into (8), together with the ambient densities of the garnet and garnet hpp phases, yields an energy of transition of $\Delta E_{\mathrm{tr}}=2.13 \mathrm{~kb} / \mathrm{g} / \mathrm{cm}^{3}$. Using point $B$ rather than the garnet hpp isotherm 
leads to a slight underestimate of $\Delta E_{t r}$; however, the difference is not significant, as will be obvious later.

Once the appropriate thermal properties of the high-pressure phase are estimated, it is possible to calculate the metastable Hugoniot data by using (3). Because values for $C_{0}$ and $s$ appearing in (4) are unknowns to be evaluated, an iteration procedure is followed. Initially, values for $C_{0}$ and $s$ are arbitrarily defined for use in the expression to calculate the Grüneisen parameter. The basic experimental Hugoniot data points are then reduced to the equivalent data points on the metastable Hugoniot. The data on the metastable Hugoniot are then indicated in the shock velocity-particle velocity plane by using (1) and (2). It has been shown by $R$ uoff [1967] that, if data in the $U_{s}-u_{\mathrm{p}}$ plane can be represented by

$$
U_{\mathrm{s}}=C_{0}+s u_{\mathrm{p}}+s^{\prime} u_{\mathrm{p}}^{2}+\cdots
$$

and if an equation of state is assumed that is based on a bulk modulus variation with pressure of the form

$$
K^{s}=K_{0}{ }^{s}+K_{0}{ }^{s} P+\frac{1}{2} K_{0}{ }^{s}{ }^{\prime \prime} P^{2}
$$

the parameters in (9) take the form

$$
\begin{gathered}
C_{0}=\left(K_{0}{ }^{s} / \rho_{0}\right)^{1 / 2} \\
s=\left(K_{0}{ }^{s^{\prime}}+1\right) / 4 \\
s^{\prime}=\left(24 C_{0}\right)^{-1} \\
\cdot\left[s\left(7-K_{0}{ }^{\prime}+4 \gamma\right)+2 K_{0}{ }^{s} K_{0}{ }^{s}\right]
\end{gathered}
$$

where

$$
\begin{aligned}
{K_{0}}^{s^{\prime}} & =\left.\left(\partial K^{s} / \partial P\right)_{S}\right|_{P=0} \\
{K_{0}}^{s^{\prime \prime}} & =\left.\left(\partial^{2} K^{s} / \partial^{2} P\right)_{S}\right|_{P=0}
\end{aligned}
$$

In most cases the uncertainty in the shock data precludes inclusion of $s^{\prime}$ and therefore of $K_{0}{ }^{8 \prime \prime}$ in the data reduction. Note that, if $K_{0}{ }^{8 \prime \prime}=$ 0 in (10), the familiar Murnaghan [1944] equation of state results. When the secondorder parameters are neglected, the elastic properties of the material may be determined from the relations

$$
\begin{gathered}
K_{0}{ }^{s}=\rho_{0} C_{0}{ }^{2} \\
\left(\partial K^{s} / \partial P\right)_{s}=4 s-1
\end{gathered}
$$

where $C_{0}$ and $s$ may be evaluated by a linear least-squares fit to the metastable Hugoniot $U_{s}-u_{p}$ data. In addition, $\left(\partial K^{s} / \partial P\right)_{s}$ may be converted to the familiar mixed derivative by

$$
\left(\partial K^{s} / \partial P\right)_{T}=\left(\partial K^{s} / \partial P\right)_{s}+\alpha T \gamma_{0} \delta
$$

where $T$ is the absolute temperature. In the iteration scheme used in this analysis, new values of $C_{0}$ and $s$ are generated for each successive repetition. These values are used in turn to evaluate $\gamma(x)$ in the following iteration. The procedure is simply repeated until convergence is attained, generally after only two or three iterations.

The results for garnet hpp are indicated in Table 3 , which examines the effects of varying each significant input parameter. The first column indicates the basic set of input data estimated by using the methods discussed previously. The remaining columns indicate the effects of varying each individual factor on the final calculated $K_{0}{ }^{8}$ and $\left(\partial K^{s} / \partial P\right)_{T}$ values for garnet hpp. Generally, each parameter was altered by an amount in excess of its estimated uncertainty. For the present problem it is apparent that the uncertainties in the estimated input parameters have little effect on the calculated elastic properties. However, a significant difference is indicated when the initial density of the high-pressure phase is varied, as is evident from data sets $a$ and $b$. A 20\% uncertainty in the calculated $K_{0}{ }^{8}$ value results from a $1.5 \%$ estimated error in initial density. Clearly, the initial density is a very sensitive parameter in shock wave high-pressure phase data reduction, and the accuracy of the final results is closely related to the uncertainty in this factor.

\section{Elastic Precursor Analysis}

It has been shown by Ahrens et al. [1968] and Graham [1971] that, when the shock wave data for $\mathrm{Al}_{2} \mathrm{O}_{3}$ are corrected for residual stress differences in the high-pressure shock state, the resulting calculated values of the bulk modulus and its first pressure derivative are more consistent with published values determined by using ultrasonic methods. The 'strength effect' occurs when the material is shocked to a state along the deformational Hugoniot and is still able to support a shear stress of magnitude $\tau$. The Hugoniot is offset above the 'hydrostatic' Hugoniot by a pressure of $\Delta P_{H}=4 / 3^{\tau}$ [e.g., Ahrens et al, 1969]. The 
TABLE 3. Input Data Reduction Sets for Garnet hpp

\begin{tabular}{|c|c|c|c|c|c|c|c|c|}
\hline $\begin{array}{l}\text { Data } \\
\text { Set }\end{array}$ & $\begin{array}{l}\text { Initial } \\
\text { Density, } \\
{\mathrm{g} / \mathrm{cm}^{3}}^{3}\end{array}$ & ${ }^{0} \mathrm{~K}^{-\mathbf{i}}$ & $\begin{array}{c}\text { Transition } \\
\text { Energy } \\
\mathrm{kb} / \mathrm{g} / \mathrm{cm}^{3}\end{array}$ & $\begin{array}{c}\text { Initial } \\
\mathrm{K}_{0}, \\
\mathrm{Mb}\end{array}$ & $\underset{6}{\text { Initial }}$ & $\delta$ & $\begin{array}{c}\text { Calculated } \\
\mathrm{K}_{0} \mathrm{~S} \\
\mathrm{Mb}\end{array}$ & $\begin{array}{l}\text { Calculated } \\
\left(\partial K^{S} / \partial P\right)_{T}\end{array}$ \\
\hline $\begin{array}{l}a^{*} \\
b \\
c \\
d \\
e \\
f \\
g \\
h\end{array}$ & $\begin{array}{l}4.44 \\
4.38\end{array}$ & $\begin{array}{l}23\left(10^{-6}\right) \\
18\left(10^{-6}\right)\end{array}$ & $\begin{array}{l}2.13 \\
1.07\end{array}$ & $\begin{array}{l}3.00 \\
2.50\end{array}$ & 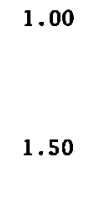 & 更 & $\begin{array}{l}3.19 \\
2.60 \\
3.19 \\
3.09 \\
3.19 \\
3.19 \\
3.23 \\
3.16\end{array}$ & $\begin{array}{l}2.6 \\
3.7 \\
2.6 \\
2.9 \\
2.6 \\
2.6 \\
2.3 \\
2.9\end{array}$ \\
\hline
\end{tabular}

*Basic data set of input parameters.

hydrostatic Hugoniot would be measured if the material retained zero strength upon shock compression.

A method for determining the stress offset from the Hugoniot elastic limit (HEL) has been suggested by Fowles [1961] and Ahrens et al. [1968]. It is assumed that the low-pressure phase behaves as a simple elastoplastic material. In this case the maximum shear stress $\tau_{\max }$ remains at the constant level reached at the HEL. The amplitude of the elastic precursor in a shock wave experiment represents the HEL and defines the maximum normal stress that the material can withstand under one-dimensional compression without shear failure occurring at the shock front. The elastic precursor stress amplitudes for the Salida garnet work are plotted in Figure 7.

The elastic precursor data were fit to a straight line by using a weighted least-squares procedure. The calculated slope is $d P / d \rho=$ $705 \pm 40 \mathrm{~kb} / \mathrm{g} / \mathrm{cm}^{3}$. The deformation accompanying a propagating planar shock front is one dimensional in the strain. In this case, along the shock front of the elastic precursor the stress-strain relation can be given by $P_{1}=$ $\mathrm{C}_{11}{ }^{B} \epsilon_{1}$, where $C_{11}{ }^{s}$ is the adiabatic second-order elastic stiffness coefficient of the garnet sample. In addition, since $\epsilon_{2}=\epsilon_{3}=0$, it can easily be shown that, to first order in strain,

$$
P(x)=C_{11}{ }^{s}(1-x)
$$

represents the elastic compression behavior. Moreover, if (17) is differentiated with respect to density and evaluated at $P=0$, it is seen that $d P / d \rho=C_{11} / \rho_{0}$. By using this relation and the previously determined slope of the elastic precursor data, a value of $2.95, \pm 0.08 \mathrm{Mb}$ was calculated for $C_{\mathrm{xi}}{ }^{\mathrm{g}}$. This value may be compared with that of $3.04 \pm 0.02 \mathrm{Mb}$ calculated previously for this parameter from acoustic measurements. The elastic behavior of the precursor data is verified by this correlation. The calculated fit to the elastic precursor data, representing one-dimensional 'elastic' deformation, is also indicated in Figure 7.

It is apparent from Figure 7 that the HEL values achieved by the individual garnet samples occur over an extended range of stress levels. The reason for this behavior is not clear; presumably, it reflects a variation in the internal strength characteristics of the individual samples, possibly related to the occurrence and the texture of microfractures or impurity inclusions or both. For the present purposes an average HEL value was calculated to represent the general strength characteristics of the Salida garnet. A value of $81 \pm 17 \mathrm{~kb}$ was computed by using a weighted average over pressure, including the 11 individual precursor stress levels. This HEL is indicated in Figure 7 and was used in determining the stress offset. A hydrostatic metastable Hugoniot appropriate for the Salida garnet was calculated by using the Hugoniot equation of state [e.g., Wang, 1969]

$P(x)=\rho_{0} C_{0}{ }^{2}(1-x) /[1-s(1-x)]^{2}$

with $C_{0}$ and $s$ values calculated from the acoustic data of Soga [1967]. The trace of the Salida garnet hydrostatic Hugoniot is shown in Figure 7. The corresponding stress offset between the average HEL and the hydrostatic Hugoniot is $\Delta P_{B}=27 \pm 7 \mathrm{~kb}$. The average maximum 


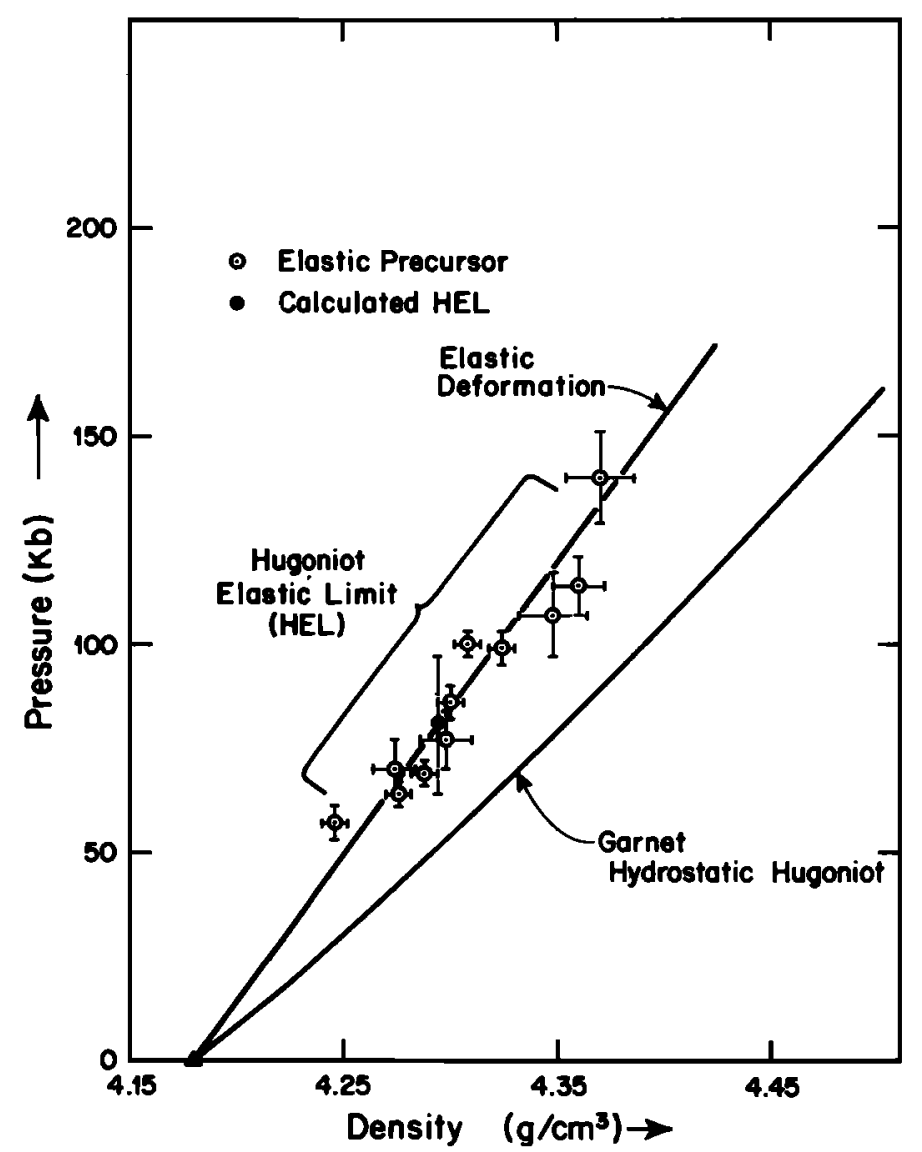

Fig. 7. Elastic precursor stress amplitudes for the Salida garnet. The offset of the HEL above the hydrostatic Hugoniot is $\mathbf{2 7} \mathbf{~ k b}$.

shear stress $\tau_{\max }$ that our samples of Salida garnet withstood under a planar shock compression in the [100] direction is thus $20 \pm 5$ $\mathrm{kb}$, according to the elastoplastic model.

It is clear from examining Figure 4 that subtracting $20 \mathrm{~kb}$ from the Hugoniot pressures of the three data points between 93 and 141 $\mathrm{kb}$ would destroy the apparently good agreement of the shock data with the $X$ ray results. It is largely for this reason that we conclude that an elastoplastic model is not an appropriate rheological model for garnet when it is shocked substantially above its HEL. Although our limited data at low pressures are not conclusive, it appears that, in fact, garnet, like quartz [Wackerle, 1962], also behaves as a fluid above the HEL, and the corresponding Hugoniot curve lies close to the hydrostat.

\section{Conclusions}

The shock wave Hugoniot data for 18 samples of almandine-garnet covering a range in pressure from 100 to over $650 \mathrm{~kb}$ clearly indicate transformation to a high-pressure phase beginning at $195 \pm 20 \mathrm{~kb}$. Density requirements demanded by the high-pressure phase Hugoniot, in conjunction with crystal chemical arguments, strongly suggest that the high-pressure phase occurs in an ilmenitelike crystal structure. The density of the garnet hpp, based on crystal chemical systematics and supported by a tentative lattice parameter determination of shockrecovered material, is calculated to be $4.44 \pm$ $0.04 \mathrm{~g} / \mathrm{cm}^{3}$; this final value and probable error represent the weighted average of the various estimates. The material elastic properties for the high-pressure phase, calculated by using the 
linear $U_{s}-u_{p}$ approximation, are $K_{0}{ }^{8}=3.19$ $\pm 0.39 \mathrm{Mb}$ and $\left(\partial K^{g} / \partial P\right)_{T}=2.6 \pm 0.7$. These values are consistent with those indicated for garnet hpp in a preliminary report by Ahrens and Groham [1972], in which a Birch-Murnaghan isentropic equation of state was used in analyzing the Hugoniot data. The isentrope for garnet $\mathrm{hpp}$, calculated from the above values by using the Murnaghan equation of state,

$$
P(\rho)=K_{0}^{s} / \beta^{T}\left\{\left[\left(\rho / \rho_{0}\right)^{\beta^{T}}\right]-1\right\}
$$

where $\beta^{T}=\left(\partial K^{s} / \partial P\right)_{r}$, is indicated in Figure 4.

In the introduction to this paper it was pointed out that a significant fraction of the upper mantle is likely to occur in the garnet structure. The primary result of the shock Hugoniot experiments on the Salida garnet is the transformation into an apparent ilmenitelike phase at relatively low pressure. The implications of this observation on the constitution of the lower mantle are important. For example, Ringwood [1969] has set up a model depicting the most probable variation of mineralogy with depth for the pyrolite composition on the basis of experimental data and crystal chemical inferences. Below the $650-\mathrm{km}$ seismic discontinuity, he suggests a homogeneous region to $1050 \mathrm{~km}$ composed of $36 \%$ ilmenite solid solution, $(\mathrm{Mg}, \mathrm{Fe}) \mathrm{SiO}_{8}-(\mathrm{Al}, \mathrm{Cr}, \mathrm{Fe})_{2} \mathrm{O}_{3} ; 55 \%$ strontium plumbate structure, $(\mathrm{Mg}, \mathrm{Fe})_{2} \mathrm{SiO}_{4}$, or, alternatively, $(\mathrm{Mg}, \mathrm{Fe}) \mathrm{SiO}_{3}$ ilmenite and $(\mathrm{Mg}, \mathrm{Fe}) \mathrm{O} ; 6.5 \%$ perovskite, $\mathrm{CaSiO}_{3} ;$ and $2.5 \%$ calcium ferrite, $\mathrm{NaAlSiO}_{4}$. When this particular model is considered, it is possible that up to $91 \%$ by weight of the silicates in this region of the mantle could be in the ilmenite structure. The results of the present work provide experimental verification that upper mantle silicates are likely to occur in the ilmenite structure within this region of the lower mantle. Furthermore, the extent of the garnet hpp stability field from the shock wave data suggests that ilmenite would be stable in the lower mantle to at least $1500 \mathrm{~km}$.

Acknowledgments. We appreciate the valuable suggestions and technical assistance of $\mathbf{J}$. $\mathbf{H}$. Lower, Rex V. Gibbons, D. Johnson, D. Newbigging, and $\mathrm{A}$. Chodos concerning various aspects of this work. J. N. Fritz's critical comments on our original manuscript also are appreciated.

This research was supported by NSF grant GA21396 and NASA grant NGL-05-002-105.

\section{ReFERENCES}

Ahrens, T. J., and E. S. Gaffney, Dynamic compression of enstatite, J. Geophys. Res., 76, 5504-5514, 1971.

Ahrens, T. J., and E. K. Graham, A shock-induced phase change in iron-silicate garnet, Earth Planet. Sci. Lett., 14, 87-90, 1972.

Ahrens, T. J., and V. G. Gregson, Jr., Shock compression of crustal rocks: Data for quartz, calcite, and plagioclase rocks, J. Geophys. Res., $69,4839-4874,1964$.

Ahrens, T. J., W. H. Gust, and E. B. Royce, Material strength effect in the shock compression of alumina, J. Appl. Phys., 99, 4610-4616, 1968.

Ahrens, T. J., D. L. Anderson, and A. E. Ringwood, Equations of state and crystal structure of high-pressure phases of shocked silicates and oxides, Rev. Geophys. Space Phys., 7, 667-707, 1969.

Ahrens, T. J., J. H. Lower, and P. L. Lagus, Equation of state of forsterite, J. Geophys. Res., 76, 518-528, 1970.

Anderson, D. L., and T. Jordan, The composition of the lower mantle, Phys. Earth Planet. Interiors, 3, 23-35, 1970.

Anderson, D. L., and H. Kanamori, Shock wave equations of state for rocks and minerals, J. Geophys. Res., 7g, 6477-6502, 1968.

Anderson, O. L., Deviation of Wachtman's equation for the temperature dependence of elastic moduli of oxide compounds, Phys. Rev., 144, $553-557,1966$.

Anderson, O. L., E. Schreiber, R. C. Lieberman, and N. Soga, Some elastic constant data on minerals relevant to geophysics, Rev. Geophys. Space Phys., 6, 461-524, 1968.

Boyd, F. R., Geological aspects of high-pressure research, Science, 145, 13-20, 1964.

Deer, W. A., R. A. Howie, and J. Zussman, Rock Forming Minerals, pp. 21-31, John Wiley, New York, 1962.

Dugdale, J. S., and D. K. C. MacDonald, The thermal expansion of solids, Phys. Rev., 89, 832-834, 1953 .

Fowles, G. R., Shock wave compression of hardened and annealed 2024 aluminum, J. Appl. Phys., 92, 1475-1487, 1961.

Gibbons, R. V., and T. J. Ahrens, Shock metamorphism of silicate glasses, J. Geophys. Res., $76, \mathbf{5 4 8 9 - 5 4 9 8 , ~} 1971$.

Graham, E. K., Elasticity and composition of the upper-mantle, Geophys. J. Roy. Astron. Soc., 20, 285-302, 1970.

Graham, R. A., Linear bulk modulus approximation for sapphire, J. Geophys. Res., 76, 4908$4912,1971$.

Hörz, F., and T. J. Ahrens, Deformation of experimentally shocked biotite, Amer. J. Sci., 267, 1213-1229, 1969.

Knopoff, L., and J. N. Shapiro, Comments on the interrelationships between Grüneisen's pa- 
rameter and shock and isothermal equations of state, J. Geophys. Res., 74, 1439-1450, 1969.

Lower, J. H., and T. J. Ahrens, Shock compression experiments with a high performance propellant gun, Bull. Amer. Phys. Soc., 11(14), 1163, 1969.

Marezio, J., J. P. Remeika, and A. Jayaraman, High-pressure decomposition of synthetic garnets, J. Chem. Phys., 45, 1821-1824, 1966.

McQueen, R. G., J. N. Fritz, and S. P. Marsh, On the equation of state of stishovite, $J$. Geophys. Res., 68, 2319-2322, 1963.

McQueen, R. G., S. P. Marsh, and J. N. Fritz, Hugoniot equation of state of twelve rocks, J. Geophys. Res., 7R, 4999-5036, 1967.

Murnaghan, F. D., The compressibility of media under extreme pressures, Proc. Nat. Acad. Sci. U.S., 30, 244-246, 1944.

O'Keeffe, D. J., Accurate pressure, volume, temperature relations for copper, J. Geophys. Res., $75,1947-1952,1970$.

Pastine, D. J., On the accuracy of the WachtmanAnderson relation, J. Geophys. Res., 75, 7421$7425,1970$.

Pastine, D. J., and J. W. Forbes, Accurate relations determining the volume dependence of the quasi-harmonic Gruneisen parameter, Phys. Rev. Lett., 21, 1582-1585, 1968.

Penfield, S. L., and F. L. Sperry, Pseudomorphs of garnets from Lake Superior and Salida, Colorado, Amer. J. Sci., 32, 307-311, 1886.

Reid, A. F., and A. E. Ringwood, High-pressure scandium oxide and its place in the molar volume relationship of dense structures of $\mathrm{M}_{2} \mathrm{X}_{3}$ and $\mathrm{ABX}_{\text {s }}$ type, J. Geophys. Res., 74, 32383252,1969 .

Rice, M. H., R. G. McQueen, and J. M. Walsh, Compression of solids by strong shock waves, in Solid State Phys., 6, 1-63, 1958.

Ringwood, A. E., The chemical composition and origin of the earth, in Advan. Earth Sci. Contrib. Int. Conf., 287-356, 1966.

Ringwood, A. E., Phase transformations in the mantle, Earth Planet. Sci. Lett., 5, 401-412, 1969.
Ringwood, A. E., Phase transformations and the constitution of the mantle, Phys. Earth Planet. Interiors, 3, 109-155, 1970.

Ringwood, A. E., and A. Major, High pressure transformation in pyroxenes, Earth Planet. Sci. Lett., 1, 351-357, 1966.

Ringwood, A. E., and A. Major, The garnetilmenite transformation in $\mathrm{Ge}-\mathrm{Si}$ pyrope solid solutions, Earth Planet. Sci. Lett., 2, 331-334, $1967 a$.

Ringwood, A. E., and A. Major, Some high-pressure transformations of geophysical significance, Earth Planet. Sci. Lett., 2, 106-110, $1967 b$.

Ruoff, A. L., Linear shock-velocity-particlevelocity relationship, J. Appl. Phys., 38, 49764980, 1967.

Slater, J. C., Introduction to Chemical Physics, pp. 238-240, McGraw-Hill, 1963.

Smith, J. V., and B. Mason, Pyroxene-garnet transformation in the Cooraro meteorite, Science, 168, 832-833, 1970.

Soga, N., The elastic constants of garnet under pressure and temperature, J. Geophys. Res., 72 , 4227-4234, 1967.

Spetzler, H., Effect of temperature and pressure on the elastic constants of polycrystalline and single-crystal $\mathrm{MgO}, J$. Geophys. Res., 75, 2073$2087,1970$.

Takahashi, T., and L. Liu, Compression of ferromagnesian garnets and the effect of solid solutions on the bulk modulus, J. Geophys. Res., 75, 5757-5766, 1970.

Wackerle, J., Shock wave compression of quartz, J. Appl. Phys., 33, 922-937, 1962.

Wang, C. Y., Phase transitions in rocks under shock compression, Earth Planet. Sci. Lett., 3, 107-113, 1967.

Wang, C. Y., Equation of state of periclase and some of its geophysical implications, J. Geophys. Res., 74, 1451-1457, 1969.

(Received January 31, 1972 ; revised September 25, 1972.) 